\title{
Introducing a Pressure Index for Water Distribution Networks’ Augmentation Planning Strategy
}

\author{
$\underline{\text { Savalan Pour Akbarkhiavi }}^{\mathrm{a}}$ and M. A. Imteaz $^{\mathrm{a}}$ \\ ${ }^{a}$ Faculty of Engineering and Industrial Science, Swinburne University of Technology, \\ Melbourne, VIC, Australia \\ Email: spourakbarkhiavi@swin.edu.au
}

\begin{abstract}
Potable Water Distribution Systems (WDS) need augmentation strategies based on a determined and pre-defined time intervals. The main aim of potable water systems augmentation is maintaining the standard and acceptable level of service after occurrences of increase in design serviced population, asset ageing and/or serviced area. It is obvious that systems augmentations require significant amount of budget allocation, which is the main constraint for the water authorities for the implementation of any augmentation plan.

In general, two main factors are playing roles in planning of WDS augmentation strategies; namely, the parameter of "Level of Service" on one hand and the factor of "Augmentation Cost" on the other. The main goal of a proper planning in a WDS is the prediction of a system's water demand in future and suggestion of an appropriate and efficient solution for the predicted demand.

Till now, no research has been conducted to establish a relationship between "Level of Service" and "Augmentation Cost". In this paper, a new index is introduced to measure the level of service of a water distribution system from its pressures point of view. Since there is no existing factor for the rating of a water network from its pressures point of view, a new factor named "Pressure Index (PI)" incorporating number of pipe nodes for five different pressure regimes is defined.

The PI factor is expected to show improvement after a WDS augmentation which is the indicator of that WDS' pressures improvement and therefore the effectiveness of proposed planning scheme. As a case study, three existing water network systems in Castlemaine area near central Victoria is investigated and relationship with the 'augmentation costs' and PI factors is presented.
\end{abstract}

Keywords: $\quad$ Level of service, water distribution system planning, augmentation cost, pressure index 
S. P. Akbarkhiavi and M.A.Imteaz, Introducing a Pressure Index for Water Distribution Networks' Augmentation Planning Strategy

\section{INTRODUCTION}

These days, cities,townships and other inhabited areas around the world are facing considerable problems to manage urban development and population growth. Under such conditions, appropriate urban water planning plays an important role to improve the effectiveness of the investments that take place in urban water systems.

The current common approach for water reticulation system planning is utilizing advanced hydraulic models (Bush, 1998), and it has been proven that these models can be used for planning purposes by simulating the existing assets and then applying future scenario loads (Alperovits, 1977). Planning is one of the outcomes of investigation on the modelled network's behavior and checking the hydraulic parameters of network such as pressures, tanks levels, and minimum and maximum flow velocities.

There are some problems involved in using of hydraulic models such as (AWWA, 1974):

- Necessity in understanding of complicated hydraulic concepts related to water networks

- Spending significant amount of time and resource for establishing the existing and future scenarios

- The notable market price of existing hydraulic model platforms

Water Distribution Systems (WDS) need augmentation strategies based on a determined time interval. The main aim of water system's augmentation is maintaining the standard and acceptable level of service after increase in serviced population/area and asset ageing. It is obvious that system augmentations are constrained by budget allocation; and every augmentation is a cost-intensive and rigorous exercise. (Alonso, 2000)

So, on one hand, the critical customer-oriented parameter is "Level of Service" and on the other the critical factor is "Augmentation Cost". (Eiger, 1994)

The main goal of "Planning" in water distribution systems is prediction of system's future demand and suggesting proper and efficient solution for that predicted demand. (The Department of Sustainability, Environment, Water, Population and Communities website)

Till now, no research has been conducted to study the relationship between "Level of Service" and "Augmentation Cost". Also, at present among water authorities there is no standard factor/scale to compare a particular augmentation option with another potential augmentation option from the level of service perspective (Tospornsampan, 2007).

\section{RESEARCH METHODOLOGY}

In this study, a new factor on water distribution systems has been defined to address the existing gap in measurement of "Level of Service". A survey has been conducted among some Victorian water authorities to get their opinions about proposed factor in WDS.

Three Victorian townships as case studies of existing WDS have been examined for the new defined parameters. For this purpose, an advanced hydraulic model has been utilised to simulate the case study WDS. In this research, InfoWorks WS has been used as the main modeling and calibration software for models. The approved augmentation options and respective costs have been used to get related information.

\section{THE CASTLEMAINE WATER SUPPLY SYSTEM}

As a case study in this paper, three townships in Castlemaine water supply system have been studied. The water system in the comprehensive Castlemaine water supply system includes the townships of Castlemaine, Chewton, CampbellsCreek, Fryerstown, Guildford, Yapeen, Harcourt, Maldon and Newstead. The current system serves a population of 13,350 residents as well as commercial and industrial customers. Approximately 7,050 properties are connected to the system (Coliban Water, Castlemaine Water Augmentation Strategy Report, 2010). A schematic view of the Castlemaine WDS is provided in Figure 1.

The focus of this paper is on the following three systems in Castlemaine WDS area:

- The Castlemaine township

- The Harcourt township

- The Campbell Creek township 
S. P. Akbarkhiavi and M.A.Imteaz, Introducing a Pressure Index for Water Distribution Networks' Augmentation Planning Strategy

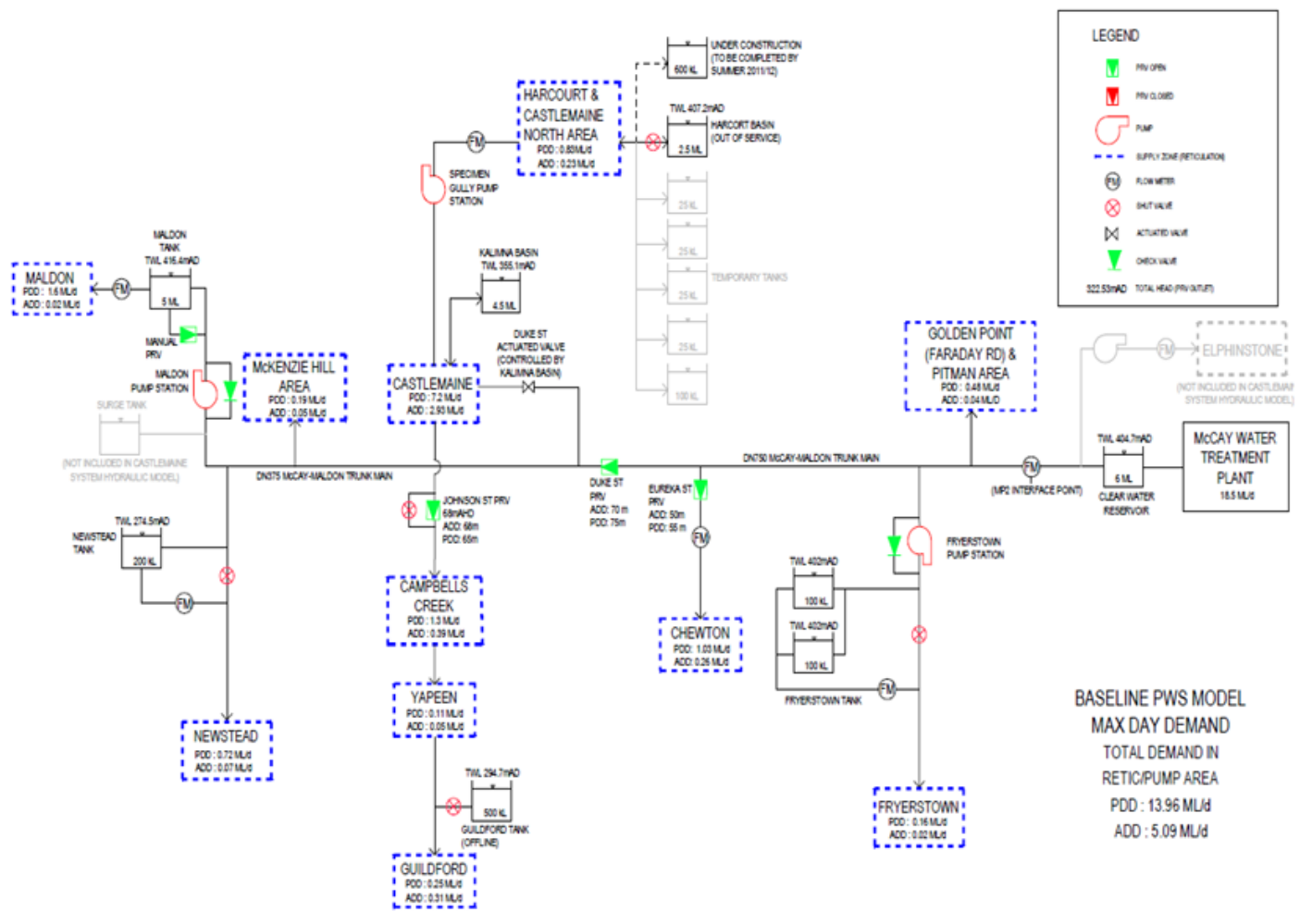

Figure 1. Castlemaine WDS schematic

\section{DEFINING Pressure Index (PI) FACTOR FOR WDS}

In this paper, pressure nodes have been categorized from pressure point of view into the following groups:

A- Nodes with maximum pressure more than $80 \mathrm{~m}$ in a 24-hr cycle in one water system

B- Nodes with maximum pressure less than $80 \mathrm{~m}$ and more than $50 \mathrm{~m}$ in a 24-hr cycle in water system

C- Nodes with pressures less than $50 \mathrm{~m}$ and more than $20 \mathrm{~m}$ in a 24-hr cycle in one water system

D- Nodes with minimum pressure less than $20 \mathrm{~m}$ and more than $5 \mathrm{~m}$ in a 24-hr cycle in water system

E- Nodes with minimum pressure less than $5 \mathrm{~m}$ and more than $0 \mathrm{~m}$ in a 24-hr cycle in one water system

F- Nodes with minimum pressure less than $0 \mathrm{~m}$ in a 24-hr cycle in one water system

Note that in the above classification, water authorities in Australia are trying to achieve group $\mathrm{C}$ and avoid the rest. (WSAA WDS Planning and Design Manual, 2004)

It is obvious that the nodes in group A are more likely to cause burst incidents in water systems. Although group B nodes pressures are acceptable from hydraulic point of view, it has been proven that from pressure management point of view the leakages and water losses will be higher in the nodes with $>50 \mathrm{~m}$ pressures.

The water authorities in Australia generally wish to have a minimum pressure of $20 \mathrm{~m}$ all the time in their water supply systems, but in some rare cases due to remoteness of demand points from water source or some topographic difficulties they do have "Supply by Agreement" contract by customers. It means just supplying water to those customers and not supplying $20 \mathrm{~m}$ minimum pressures. We have defined this group of customers as group D in our classification.

Group E belongs to nodes which experience a minimum pressure of $5 \mathrm{~m}$ or less and never experience a negative pressure. This category is not acceptable for water authorities but in rare situation can be adopted.

All nodes which experience any negative pressure during a 24-hr water cycle in water systems have been labeled as group $\mathrm{F}$. 
S. P. Akbarkhiavi and M.A.Imteaz, Introducing a Pressure Index for Water Distribution Networks' Augmentation Planning Strategy

Presently, with the factors and tools which we have access to, we are not able to rate a water network from its pressure point of view. In other words, we do not have any tool, parameter or factor to measure the efficiency of a water distribution network from the quality of its pressure point of view.

Also, currently we do not have any tool to compare the improvement of a water network before and after an augmentation plan. Consequently, we do not know how much money to invest on a particular network to bring the pressures back to standard level of service. In fact, we even do not know what the "Standard Level of Service" is for pressures in a whole water distribution system.

The main driver of this research is to define and introduce some new factors or index to address the mentioned issues and then use that factor to measure and/or rate a WDS before and after a proposed augmentation.

The new factor defined in this research has been named as the Pressure Index (PI). The PI is a dimensionless factor, and by defining that and observing its change before and after a network augmentation, we will be able to find the relationship between the improvements of a water supply network performance on one hand the cost for that improvement on the other.

In this research, it is aimed to find out how much money to spend on a water distribution system to change PI from point $\mathrm{A}$ to $\mathrm{B}$.

For this purpose, firstly the acceptable range of PI in case study Town's water supply system should be found or defined.

The main criterion in measurement of level of service in WDS is the occurred pressures in the water supply system. Currently, there is no factor or index to measure a WDS from the status of its pressure point of view.

In this research, a new factor as an indicator of WDS performance from the pressure point of view is introduced.

Based on consultation with different authorities, PI is defined via following equation:

$$
\mathrm{PI}=\frac{\mathrm{Nt}}{\left(\alpha \cdot\left(\mathrm{N}_{-\infty}^{0}\right) \beta \cdot\left(\mathrm{N}_{0}^{5}\right)+\gamma \cdot\left(\mathrm{N}_{5}^{20}\right)+\delta \cdot\left(\mathrm{N}_{50}^{80}\right)+\lambda \cdot\left(\mathrm{N}_{80}^{\infty}\right)\right)+\mathrm{Nt}}
$$

where,

$\mathrm{Nt}=$ Number of total customers in the study system

$\left(\mathrm{N}_{80}^{\infty}\right)=$ Number of customers experience maximum pressure greater than $80 \mathrm{~m}$ (Group A)

$\left(\mathrm{N}_{50}^{80}\right)=$ Number of customersexperience maximum pressure less than $80 \mathrm{~m}$ and greater than $50 \mathrm{~m}$ (Group B)

$\left(\mathrm{N}_{5}^{20}\right)=$ Number of customersexperience minimum pressure less than $20 \mathrm{~m}$ and greater than $5 \mathrm{~m}$ (Group D)

$\left(\mathrm{N}_{0}^{5}\right)=$ Number of customersexperience minimum pressure less than $5 \mathrm{~m}$ and greater than 0m (Group E)

$\left(\begin{array}{c}\mathrm{N}_{-\infty}^{0}\end{array}\right)=$ Number of customersexperience minimum pressure less than 0m (Group F)

$\alpha, \beta, \gamma, \delta$ and $\lambda=$ Weight factors that show to what extent we dislike the pressure group and they are to be determined by local water authorities

\subsection{Assumption for Weightage Factors}

The PI index is sensitive to the nominated weightage factor of each pressure category. Since the PI index is defined in the way to be flexible in pressures categories range and weightage factors, they can be modified based on priorities of each water authority. In this paper, based on discussions with a number of Victorian authorities, the adopted figures for Weightage Factors are as following:

$$
\alpha=20, \beta=5, \gamma=3, \delta=1, \lambda=2
$$

By adopting the mentioned Weightage Factors, the PI index will be as following:

$$
\mathrm{PI}=\frac{\mathrm{Nt}}{\left.20 \cdot\left(\mathrm{N}_{-\infty}^{0}\right)+5 \cdot\left(\mathrm{N}_{0}^{5}\right)+3 \cdot\left(\mathrm{N}_{5}^{20}\right)+1 \cdot\left(\mathrm{N}_{50}^{80}\right)+2 \cdot\left(\mathrm{N}_{80}^{\infty}\right)\right)+\mathrm{Nt}}
$$


S. P. Akbarkhiavi and M.A.Imteaz, Introducing a Pressure Index for Water Distribution Networks' Augmentation Planning Strategy

\section{RESULT OF SAMPLE STUDY}

For the purpose of this study, the PI for Castlemaine, Campbells Creek / Guildford and Harcourt pressure zones for projected and approved demands for horizon years of 2013, 2018, 2023 and 2038 have been calculated for two scenarios (see Table 1):

- Without water network augmentation

- With approved water network augmentation

Table 1. Summary of expected augmentation cost and PI improvements (costs are for target year)

\begin{tabular}{|c|c|c|c|c|c|c|c|c|c|}
\hline & \multicolumn{3}{|c|}{ Campbells Creek } & \multicolumn{3}{c|}{ Castlemaine } & \multicolumn{3}{c|}{ Harcourt } \\
\hline Year & $\begin{array}{c}\text { PI } \\
\text { (before) }\end{array}$ & $\begin{array}{c}\text { PI } \\
\text { (after) }\end{array}$ & $\begin{array}{c}\text { Augmentation } \\
\text { costper capita } \\
(\$)\end{array}$ & $\begin{array}{c}\text { PI } \\
\text { (before) }\end{array}$ & $\begin{array}{c}\text { PI } \\
\text { (after) }\end{array}$ & $\begin{array}{c}\text { Augmentation } \\
\text { costper capita } \\
(\$)\end{array}$ & $\begin{array}{c}\text { PI } \\
\text { (before) }\end{array}$ & $\begin{array}{c}\text { PI } \\
\text { (after) }\end{array}$ & $\begin{array}{c}\text { Augmentation } \\
\text { costper capita } \\
(\$)\end{array}$ \\
\hline 2013 & 0.12 & 0.43 & 823 & 0.23 & 0.46 & 812 & 0.17 & 0.47 & 798 \\
\hline 2018 & 0.07 & 0.43 & 772 & 0.20 & 0.47 & 790 & 0.06 & 0.48 & 785 \\
\hline 2023 & 0.05 & 0.43 & 723 & 0.17 & 0.44 & 765 & 0.15 & 0.46 & 742 \\
\hline 2038 & 0.04 & 0.40 & 733 & 0.15 & 0.42 & 775 & 0.11 & 0.49 & 750 \\
\hline
\end{tabular}

Figure 2 shows the PI factor improvement in three case study townships based on approved augmentation strategies for the horizon year by respective water authority.

The upper group of lines show the PI factor after consideration of approved augmentation strategies and the lower lines indicate the PI factor in scenario of "no augmentation" in the horizon year. The Y axis in Figure 2 shows the PI factor and the $\mathrm{X}$ axis shows the horizon years.
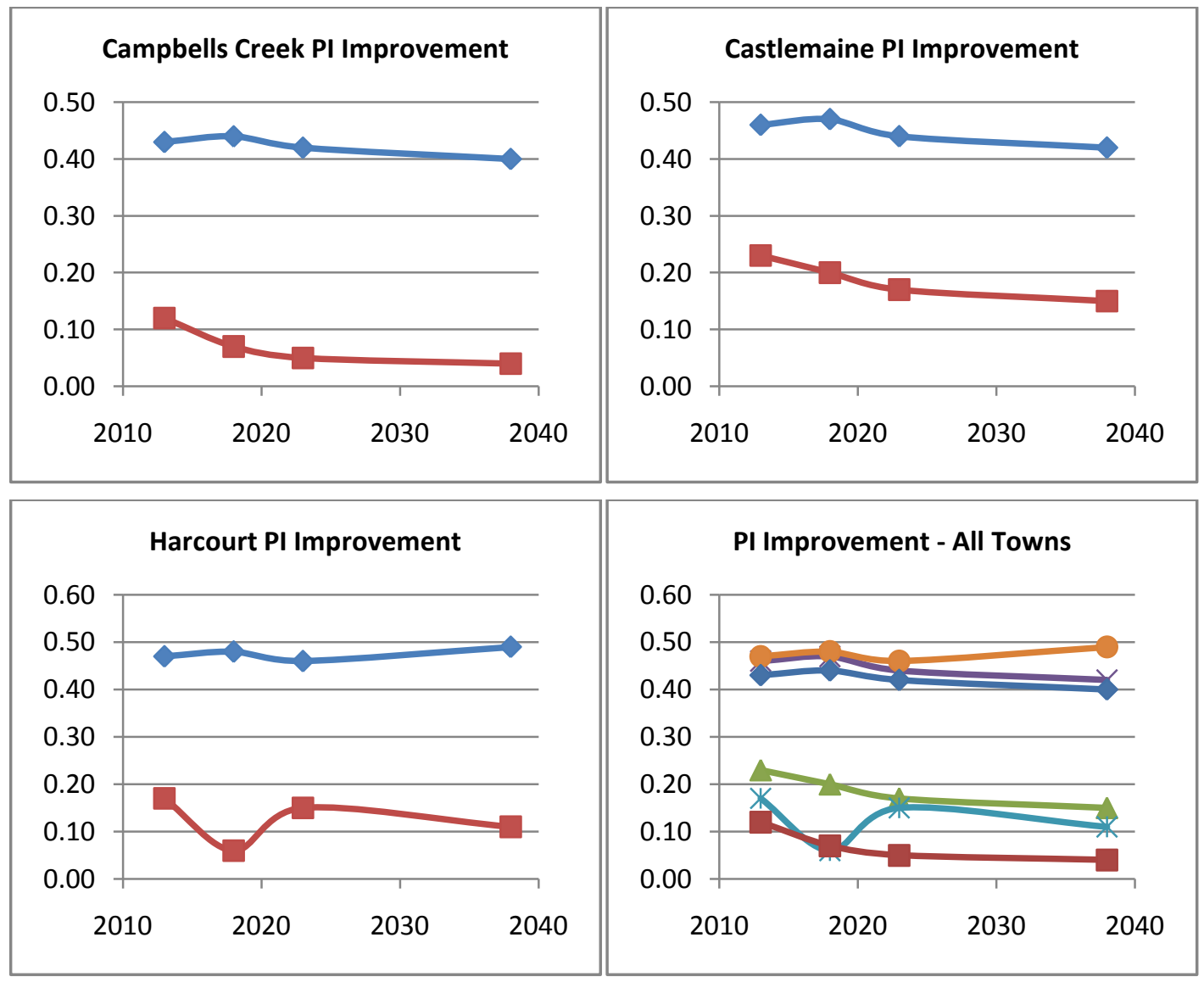

Figure 2. Pressure Index improvement in case study area 
S. P. Akbarkhiavi and M.A.Imteaz, Introducing a Pressure Index for Water Distribution Networks' Augmentation Planning Strategy

Figure 3 shows the assigned cost per capita for various horizon years based on approved population projection and augmentation strategy cost for three case study townships.

The augmentation costs have been adopted after option assessment and multi-criteria assessment procedure held in the respective water authorities. The Y axis in Figure 3 shows the allocated budget per capita $(\$ / \mathrm{p})$ and the $\mathrm{X}$ axis shows the horizon years.
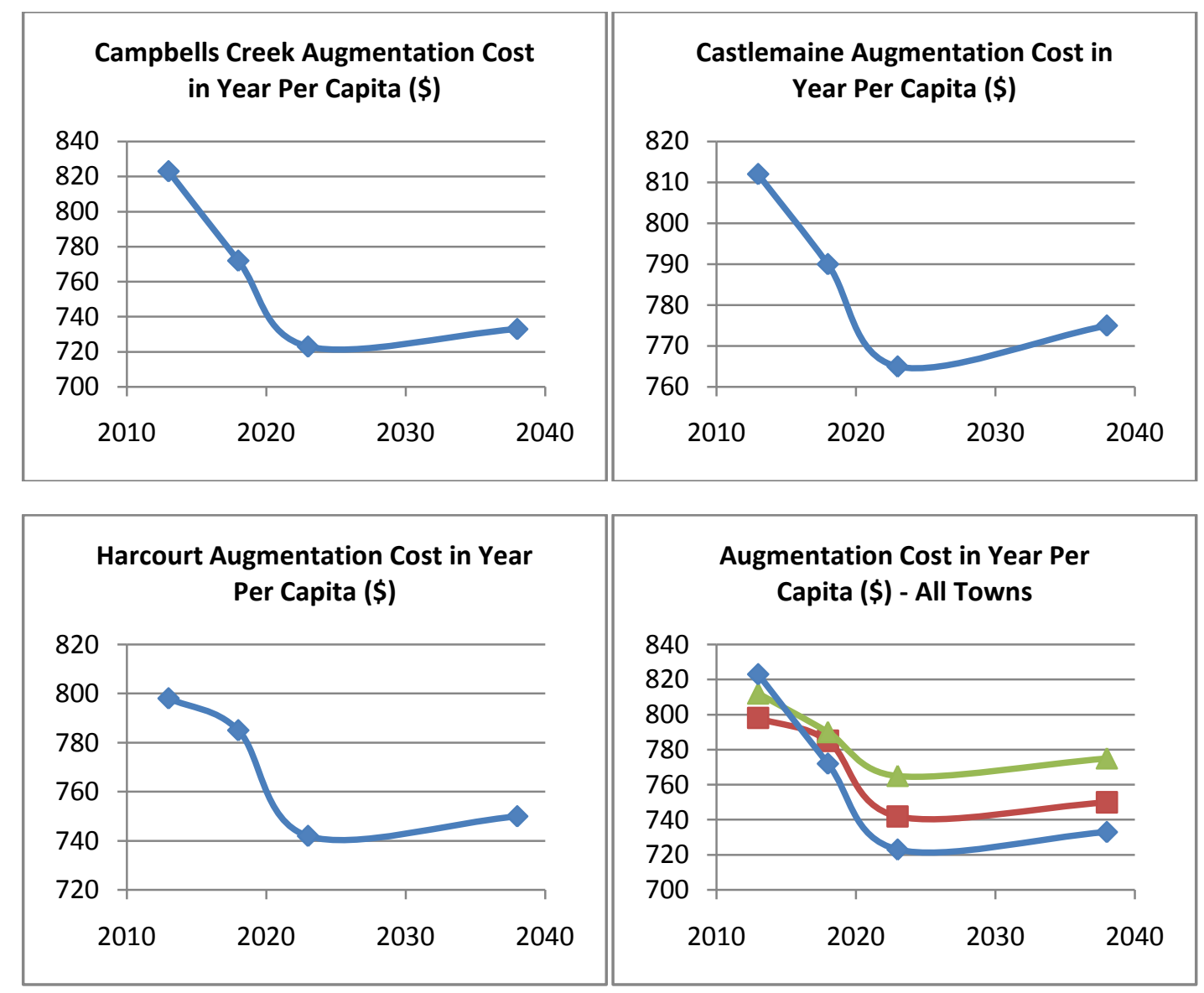

Figure 3 - Approved augmentation cost inhorizon year in the case study area

Figure 4 shows the ultimate PI factor for approved augmentation strategy versus assigned cost per capita for the three case study townships. This comparison shows the distribution of approved PI and allocated budget for achieving the accepted PI. The Y axis in Figure 4 shows the allocated budget per capita (\$/p) and the X axis shows the respective calculated PI factor.

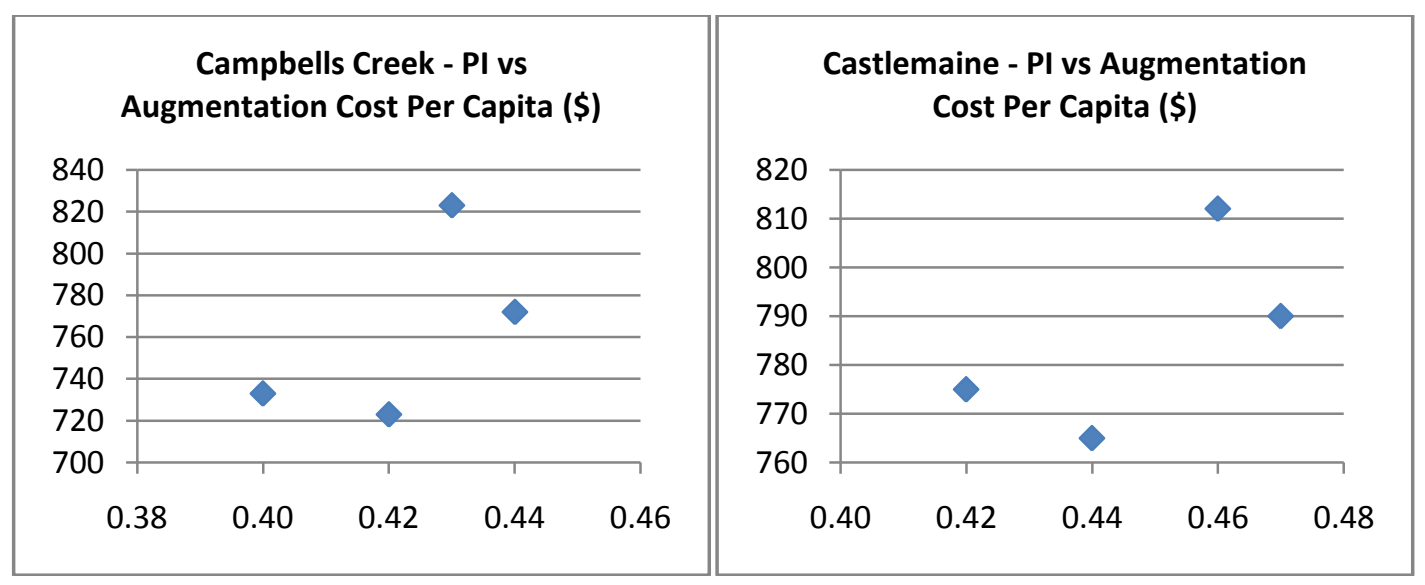


S. P. Akbarkhiavi and M.A.Imteaz, Introducing a Pressure Index for Water Distribution Networks' Augmentation Planning Strategy

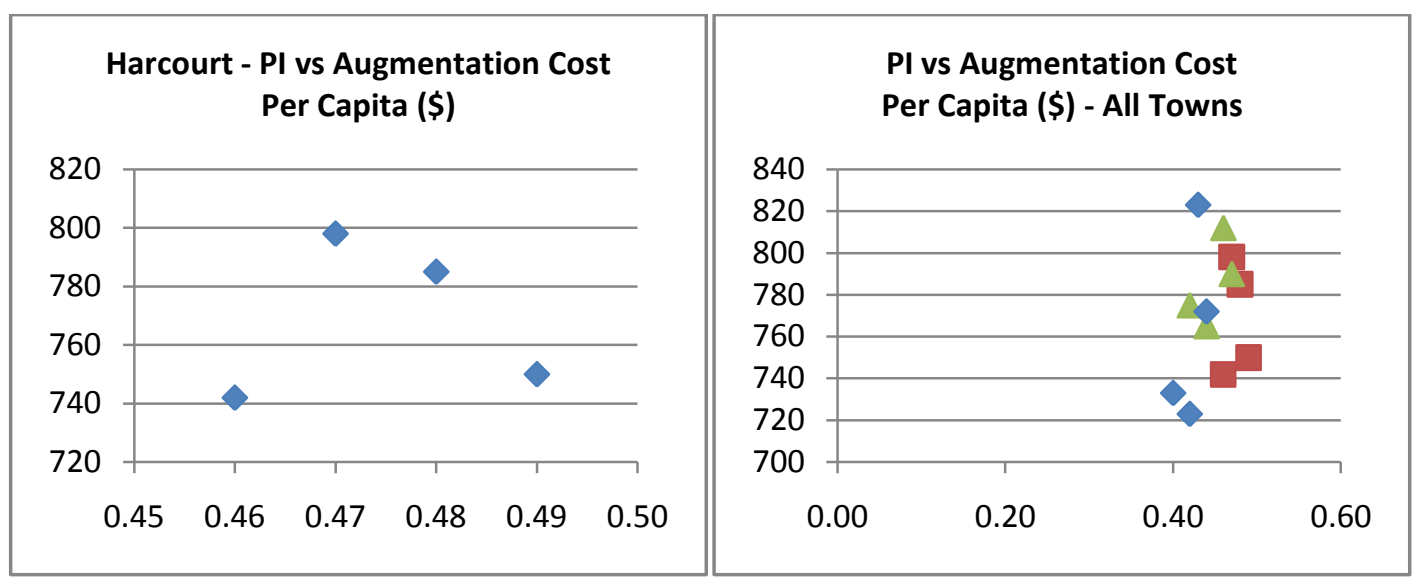

Figure 4. Pressure index factor for approved augmentation strategy versus allocated budget

\section{DISCUSSION AND CONCLUSIONS}

A new factor named as "Pressure Index" (PI) in Water Distribution Systems (WDS) has been defined in this research for the measurement of WDS level of service based on occurring water pressures in the system in current and future populations. This study has been carried out for three Victorian townships in Castlemaine WDS area as a case study.

The research has shown that the PI factor drops by population increase in the case study townships and by applying the approved augmentation, the PI factor rises to the range of $(0.4-0.5)$. This range seems to be the minimum PI factor for an acceptable level of service provided by the approved augmentation strategy.

This research has found that, in the case study townships, the budget in the range of $(\$ 720-\$ 820)$ per capita is needed for each horizon year as augmentation cost to achieve the PI in the minimum acceptable range of $(0.4-0.5)$.

It is notable that the introduced methodology in this paper can be elaborated further for other populated areas around the world considering the local "Level of Service" regulations for minimum and maximum pressures.

\section{REFERENCES}

Bush, C.A., and Uber, J.G., "Sampling Design Methods for Water Distribution Model Calibration", J. of Water Res. Plan.and Man., ASCE, 124(6) ,334- 344, 1998.

Alperovits, E., and Shamir, U., "Design of Optimal Water Distribution System” Water Resources Research, 13: 885-900, 1977.

AWWA, "Water-Distribution Research \& Development Needs." Journal of the American Water Works Association. pp. 385-390, June 1974.

Alonso, J. M., Alvarruiz, F., Guerrero, D., Hernández, V., Ruiz, P. A., Vidal, A. M., Martínez, F., Vercher, J., and Ulanicki, B. (2000)."Parallel computing in water network analysis and leakage minimization."Journal of Water Resources Planning and Management, 126(4), 251-260.

Eiger, G., Shamir, U., and Be-Tal, A., "Optimal Design of Water Distribution Networks." Water Resour. Res., 30(9), 2637-2646, 1994.

The Department of Sustainability, Environment, Water, Population and Communities website, Australian National principles for urban water planning

Tospornsampan, J., Kita, I., Ishii, M., and Kitamura, Y. (2007 ). "Split-pipe design of water distribution network using simulated annealing." International Journal of Computer, Information, and Systems Science, and Engineering, 1(3), 153-163.

Coliban Water (2010), Castlemaine Water Augmentation Strategy Report

WSAA (2004), Australian Water Distribution System Planning and Design Manual 